\title{
Glottic impersonation
}

\author{
George Kovacs, MD, MHPE, FRCPC • Laura V. Duggan, MD, FRCPC • \\ Peter G. Brindley, MD, FRCPC
}

Received: 14 December 2016/Accepted: 15 December 2016/Published online: 27 December 2016

(C) Canadian Anesthesiologists' Society 2016

Observing the endotracheal tube (ETT) pass through the vocal cords is widely taught and promoted as a means to ensure correct ETT placement. However, in isolation, this may be an insufficient way to determine success. The accompanying image is from a clinical grade, lightly embalmed, cadaver used in the teaching of an advanced airway course; the cadaveric airway is clinically indistinguishable from that of a live patient in terms of its tissue responsiveness. It shows how forceful video laryngoscopy, direct laryngoscopy, or even bag-mask ventilation, can distort the esophageal opening (E) causing the esophagus to "impersonate" the glottic (G) opening. This could fool the laryngoscopist into inserting the ETT into the esophagus while insisting it was correctly placed in the trachea. Arguably, this could be even more likely during emergency airway situations due to stressinduced aggressive laryngoscopy and impaired decisionmaking. This image highlights why seeing the ETT go through the vocal cords may not be as "gold" a standard for confirmation of correct ETT placement as it was once thought and has now been usurped by waveform capnography or bronchoscopy.

G. Kovacs, MD, MHPE, FRCPC ( $\square)$

Departments of Emergency Medicine, Anaesthesia, Medical

Neuroscience, Dalhousie University, Halifax, NS, Canada

e-mail: gkovacs@dal.ca

\section{V. Duggan, MD, FRCPC}

Department of Anesthesiology, Pharmacology and Therapeutics,

University of British Columbia, Vancouver, BC, Canada

\section{P. G. Brindley, MD, FRCPC}

Department of Critical Care, University of Alberta, Edmonton,

$\mathrm{AB}$, Canada

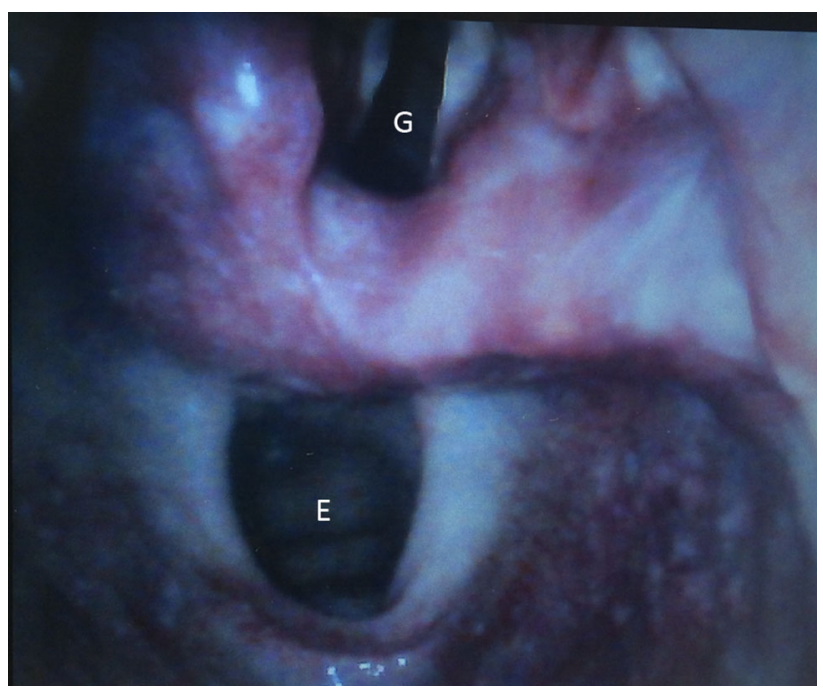

Figure A videolarynogoscopic image of a lightly embalmed cadaveric airway showing how forceful laryngoscopy can distort the tissues such that the esophageal opening (E) might be confused with the normal glottic opening $(\mathrm{G})$ thus impersonating it

\section{Conflicts of interest None declared.}

Editorial responsibility This submission was handled by Dr. Hilary P. Grocott, Editor-in-Chief, Canadian Journal of Anesthesia. 